\title{
Impacto distributivo del gasto público en educación universitaria en España: un análisis de incidencia normativa para el nuevo milenio*
}

\section{LAURA DE PABLOS ESCOBAR}

Departamento de Economía Aplicada VI (Hacienda Pública y Sistema Fiscal), UNIVERSIDAD COMPLUTENSE DE MADRID, ESPAÑA. E-mail: lpablos@ccee.ucm.es

\section{MARÍA GIL IZQUIERDO}

Departamento de Economía Aplicada, UNIVERSIDAD AUTÓNOMA DE MADRID, ESPAÑA. E-mail: maria.gil@uam.es

\begin{abstract}
RESUMEN
El trabajo presenta un análisis de la incidencia normativa del gasto público en educación universitaria durante los años 2000 y 2004 para el caso español. Las bases de datos utilizadas son el Panel de Hogares de la Unión Europea 2000 y la Encuesta de Condiciones de Vida 2004. En el estudio se aportan interesantes novedades metodológicas en la aplicación empírica del concepto de incidencia normativa. En este sentido, se consideran diferentes escalas de equivalencia; también se ajusta el gasto a imputar teniendo en cuenta las diferentes ramas de educación universitaria, el género y la región de procedencia del estudiante. Los resultados se ofrecen desde una doble perspectiva regional y nacional, constatándose una incidencia del gasto en España más progresiva y redistributiva en el nuevo milenio que en décadas anteriores.
\end{abstract}

Palabras clave: Incidencia normativa, educación universitaria, incidencia regional

\section{Distributive Impact of Public Expenditure in Higher Education: A Benefit Incidence Analysis for the New Millennium}

\begin{abstract}
This paper presents a Benefit Incidence Analysis for Higher Education public expenditure in 2000 and 2004, in Spain. As databases, the European Community Household Panel (ECHP) 2000 and the Living Conditions Survey (EU-SILC) 2004 are used. In this study, new and interesting methodological issues are introduced when applying the Benefit Incidence concept. In this sense, different equivalence scales are considered; besides, imputed expenditure is adjusted, taking into account different university education fields, gender issues and students' original region. Results are offered following a double regional and national perspective, showing that this expenditure is more progressive and redistributive in Spain in the new millennium rather than during previous decades.
\end{abstract}

Keywords: Benefit Incidence, Higher Education, regional Incidence.

Clasificación JEL: D31, I21

\footnotetext{
* Las autoras agradecen los comentarios y sugerencias efectuados por dos evaluadores anónimos. Cualquier error u omisión que permanezca en el mismo es de exclusiva responsabilidad de las autoras
}

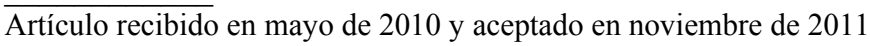

Artículo disponible en versión electrónica en la página www.revista-eea.net, ref. ə-29102 


\section{INTRODUCCIÓN}

El objetivo del presente trabajo es la evaluación de la incidencia distributiva del gasto público en educación universitaria para el caso español. Los estudios de incidencia se encuadran dentro del análisis de la función distributiva del sector público. Tradicionalmente, estos estudios han estado centrados en el análisis de los impactos de los ingresos públicos. Sin embargo, ante la escasa capacidad redistributiva que en la actualidad tienen los ingresos públicos y la tendencia a la proporcionalidad de los sistemas impositivos (Harberger, 2004; Calero, 2001), los gastos públicos se han convertido en el instrumento más potente con que cuentan los gobiernos para redistribuir renta. A través de estos gastos, los gobiernos quieren mejorar el bienestar de sus ciudadanos, y contribuir a una mejora de la distribución de la renta y la riqueza. En este contexto, la evaluación de cuáles son los impactos distributivos de los gastos públicos se ha hecho necesaria y relevante.

Existen varias alternativas metodológicas a la hora de aproximarse al cálculo de la incidencia distributiva. De Wulf (1981) ofrece cuatro alternativas. La Incidencia Impacto fija su atención en los receptores de los pagos realizados por el gobierno. Se trata de un análisis contable, en el que el gasto es un flujo monetario que se dirige hacia personas o regiones. La Incidencia Normativa o Legal iguala los beneficios de los gastos públicos a los costes de producción. El análisis se realiza identificando los beneficiarios y analizando el incremento en las rentas propiciado por los programas de gasto público. La Incidencia del Gasto o en los Precios Relativos investiga la forma en que los efectos del gasto público sobre los precios de los productos y los factores de producción influyen en la situación de renta de las familias o de otras unidades económicas. Finalmente, la Incidencia del Beneficio trata de estudiar cómo valoran los servicios gubernamentales sus beneficiarios, diferenciándose del enfoque que identifica costes con beneficios, y prolongando el análisis a largo plazo. Este enfoque trata de medir cómo cada tipo de gasto afecta al bienestar de los beneficiarios y expresar los resultados en términos de la utilidad que proporcionan $^{1}$.

Sin embargo, la mayoría de estas definiciones, que abarcan desde conceptos de incidencia muy simples hasta nociones de incidencia mucho más completas y consistentes, adolecen de un problema fundamental: las dificultades que se plantean a la hora de su posible aplicación empírica. Estas dificultades son las que, al menos en cierta medida, justifican que el enfoque de incidencia normativa sea el más utilizado a nivel empírico.

El presente trabajo retoma los estudios tradicionales de incidencia normativa de los gastos públicos, incorporando una serie de aportaciones relevantes. Se

\footnotetext{
${ }^{1}$ Una descripción detallada de estos métodos puede encontrarse en De Pablos y Valiño (2000).
} 
realiza un estudio de incidencia normativa del gasto público en educación universitaria $^{2}$ para los años 2000 y 2004 en España, introduciendo importantes novedades metodológicas con respecto estudios anteriores. Entre éstas, cabe destacar lo novedoso de las bases de datos utilizadas, la unidad de análisis escogida, las escalas de equivalencia que se aplican y los criterios de imputación del gasto, que incorporan cuestiones de género, de especialidad de estudios y de movilidad universitaria. Además, los resultados se presentan a nivel nacional y regional, aspecto éste de gran importancia desde que en 1996 se produjera la descentralización de este gasto hacia las regiones.

El trabajo se estructura en cuatro epígrafes más conclusiones. En primer lugar, se ofrece una aproximación teórica al concepto de incidencia normativa, aportando un análisis de las ventajas y limitaciones de este método. Asimismo, se ofrece una síntesis de la metodología y resultados de los principales estudios de incidencia de la educación universitaria realizados en nuestro país. En segundo lugar, se explican las principales novedades metodológicas que se aportan en nuestro trabajo. A continuación, se realiza un análisis empírico de incidencia normativa del gasto público en enseñanza universitaria para el conjunto de España, y se presenta una síntesis de los principales resultados alcanzados. En cuarto lugar, se aporta un análisis territorial de la incidencia de este gasto. Finalmente, se hace un resumen de las principales conclusiones.

\section{ANÁLISIS APLICADO DE LA INCIDENCIA NORMATIVA: REVISIÓN DE ALGUNAS APORTACIONES RECIENTES}

La incidencia normativa o legal ${ }^{3}$ mide el impacto inmediato que tiene el gasto público en las rentas de los beneficiarios. Es el enfoque de incidencia del gasto público más utilizado en los estudios empíricos realizados en nuestro país.

\footnotetext{
${ }^{2}$ Con la denominación genérica de educación superior se puede englobar en España a toda la enseñanza postsecundaria. Hasta épocas recientes, educación superior y universitaria eran utilizados como conceptos equivalentes en nuestro país, ya que la educación universitaria es la que recoge gran parte de los estudios superiores, con más del $86,45 \%$ de los alumnos, y es el nivel al que nos referiremos en este trabajo. El 13,55\% restante está compuesto por un conjunto de enseñanzas que se pueden agrupar en tres categorías: estudios que ofrecen una titulación equivalente a la universitaria pero que, por su carácter específico, no se imparten en la universidad (enseñanzas artísticas de grado superior y la enseñanza superior militar); un conjunto de enseñanzas que se rigen por disposiciones legislativas específicas y que ofrecen una titulación propia no equiparable con el resto de los estudios mencionados; y, por último, la formación profesional de grado superior, que ofrece una titulación postsecundaria. En España culminó su implantación durante el curso 2002-2003, aumentando desde entonces significativamente el número de alumnos matriculados en estos niveles educativos (entre el curso 1999-2000 y 2006-2007, se produce una tasa de variación de estos alumnos 43,95\%).

${ }^{3}$ Véanse Gil (2001), De Pablos y Valiño (2000), Calero (1996), Barea et al. (1990) para una explicación detallada del concepto de incidencia normativa de los gastos públicos, así como de las fases que usualmente se siguen al aplicar empíricamente esta metodología.
} 
Los supuestos teóricos de este enfoque parten del supuesto de que el valor que los consumidores otorgan a un servicio público es igual al coste de su provisión. A continuación, se asignan los beneficios o subsidios públicos a los usuarios del servicio, ordenados a través de una variable que aproxime su poder adquisitivo. De este modo, se consigue un perfil de la distribución de una categoría específica de gasto público, a través de la distribución del indicador de poder adquisitivo en el corto plazo. Por último, se estudia cuáles son los impactos en términos de desigualdad del gasto público analizado. En resumen, el objetivo de este tipo de estudios es el de comparar la situación de la unidad de análisis teniendo en cuenta el gasto publico realizado en un determinado programa, con una situación hipotética en la que no se realizara dicho gasto.

Como principales ventajas de esta metodología, Van de Walle (1998) señala que se trata de una técnica fácilmente comprensible, cuyos resultados se presentan de forma sencilla y pueden ser extremadamente potentes. En la mayoría de casos, al desconocerse la función de bienestar social subyacente a las políticas de gasto de un determinado país, los estudios de incidencia normativa pueden convertirse en un instrumento con una gran influencia sobre la necesidad de reasignaciones presupuestarias y reformas, así como de políticas de desarrollo. En este sentido, estos análisis se pueden considerar como una primera aproximación para conocer a los beneficiarios reales del gasto público y saber si el dinero que se gasta va a parar a los estratos más necesitados ${ }^{4}$.

A pesar de lo dicho anteriormente, el enfoque de incidencia normativa también cuenta con desventajas que conviene tener presentes y que son consecuencia directa, fundamentalmente, de los supuestos teóricos en los que se basa. Por ejemplo, se puede señalar (Van de Walle, 1998) que el coste de provisión de un servicio puede tener poco que ver con los beneficios que supone para el individuo, ofreciendo una visión incompleta de los efectos en el bienestar, ya que no se tienen en cuenta, entre otros, los beneficios indirectos o externalidades de los gastos públicos pueden ocasionar. Otra limitación es que se parte del supuesto de que existe un mundo sin gasto público (contrafactual): esto es, se compara a los individuos sin un determinado gasto público y con él, sin tener en cuenta que las políticas públicas pueden afectar al comportamiento económico del individuo, a sus decisiones de oferta de trabajo, consumo, ahorro e inversión. Como balance final de ventajas e inconvenientes, cabe destacar que esta metodología facilita el conocimiento, de forma bastante precisa e inmediata, de los impactos distributivos en renta de las políticas de gasto.

\footnotetext{
${ }^{4}$ Estudios con gran peso en instituciones como el Fondo Monetario Internacional (F.M.I.), el Banco Mundial o la Comisión Económica para América Latina y el Caribe (C.E.P.A.L.) han supuesto la expansión en el uso y la mejora de esta técnica, y han significado la proliferación de los análisis de incidencia normativa del gasto en numerosos países, lo que ha permitido realizar comparaciones internacionales.
} 
Además, al ser este enfoque el más utilizado a nivel empírico, permite un cierto seguimiento de la evolución de los resultados alcanzados a lo largo del tiempo.

A raíz de lo anterior, se aprecia el notable interés suscitado en torno al conocimiento aplicado del impacto distributivo del los gastos públicos, siendo importante el número de trabajos aparecidos en España durante las últimas décadas. En líneas generales, los resultados de estos estudios ${ }^{5}$ muestran, hasta 1995, una cierta regresividad en la incidencia del gasto público en educación universitaria, mayor para el sistema de becas. A partir de dicho año, las aportaciones realizadas muestran resultados más igualitarios incluso progresivos en el caso de España. En otros países, la regresividad se confirma también en el nuevo milenio.

Como rasgos metodológicos generales de buena parte de los trabajo realizados, cabe citar los siguientes: aplican el enfoque de incidencia normativa del gasto en educación universitaria, utilizando, en general, como bases de datos las Encuestas Básicas de Presupuestos Familiares 1980-81 y 1990-91; analizan, de forma general, tanto la incidencia de las subvenciones como la de las becas; el hogar es la unidad de análisis considerada y se corrige la capacidad económica de los mismos aplicando la escala de equivalencia clásica de la OCDE. Generalmente, se elige la renta disponible como renta original; y el gasto en educación universitaria que se imputa a los hogares es el coste medio per capita de la educación universitaria entre el número de estudiantes.

Como aportaciones singulares recientes e interesantes, cabe mencionar las siguientes, ordenadas en dos tipologías distintas, según que el objetivo de análisis sea de carácter personal (individuo u hogar) o regional.

\subsection{Incidencia normativa personal}

De los estudios realizados en España en los últimos diez años que analizan la incidencia personal del gasto universitario, destaca el trabajo de Calero (1996). En este trabajo, el autor siguiendo, a grandes rasgos, las decisiones metodológicas anteriormente apuntadas, llega a la conclusión que desde 1980 a 1990, existe un impacto regresivo del gasto público en educación universitaria, si bien esta regresividad se reduce en los años noventa, produciéndose incrementos de la incidencia especialmente en las decilas medias. El autor realiza tres estimaciones distintas: la primera supone calcular para cada decila parcial el ingreso y el gasto medio declarados, asignando a cada familia el valor mayor de éstos; la segunda corrige la anterior a través de la escala de

5 Los resultados de los trabajos de incidencia del gasto público en educación superior realizados hasta 1995, tanto a nivel nacional como internacional, se resumen en Pérez y Utrilla (1996) 
equivalencia de la OCDE, y la tercera, parte de la renta equivalente calculada con la escala OCDE clásica y filtra a los hogares para el caso de que el sustentador principal tenga entre 45 y 65 años. Posteriormente, se obtiene la distribución de estudiantes por decilas de renta y el gasto a imputar (para cada corrección). Los resultados, como anticipábamos, apuntan a una cierta regresividad en los años ochenta, menor en los noventa, pero que resulta acentuada en el caso de las becas. A resultados similares llega Pérez (1996a) utilizando parámetros metodológicos también similares. Esta autora también ofrece un resultado adicional interesante: en el caso concreto de las becas su impacto resulta ser ligeramente regresivo cuando se tiene en cuenta como índice de bienestar los ingresos, mientras que no se observa dicho impacto si el índice que se toma es el de gasto de los hogares. Por último, la autora encuentra que las subvenciones públicas entregadas directamente a las universidades son las que muestran un comportamiento más regresivo. Por su parte, Gimeno (2000) presenta como novedad metodológica importante la inclusión, como parte del gasto o costes de la educación universitaria a imputar, de la cifra estimada de amortización de capital fijo social para cada una de las funciones delimitadas. Coincidiendo con la mayoría de estudios, y estimando los beneficios del gasto público entre los hogares de las distintas decilas, en términos del gasto medio correspondiente, se obtiene que la compensación de tasas en el nivel educativo universitario es la que presenta una distribución más regresiva (moda: novena decila, mediana: octava). Finalmente, merece la pena mencionar el trabajo de Calero (2002) donde por primer vez se utiliza el Panel de Hogares de la Unión Europea, (año 1995) para el análisis de la incidencia normativa de la educación universitaria. Las principales aportaciones de este trabajo son las siguientes: presentación de una amplia batería de indicadores de desigualdad, progresividad y redistribución; consideración de los gastos fiscales e incorporación de los gastos de capital; utilización de la escala de equivalencia de Buhmann et al. (1988); y muy especialmente, consideración de una incidencia diferencial entre distintos grupos sociales, con especial atención sobre la situación de las clases medias. Los principales resultados del estudio apuntan a que las clases medias no son las principales beneficiarias del gasto público en educación universitaria y a que el impacto distributivo es muy distinto entre las diferentes clases sociales.

Para otros países, los resultados apuntan de forma clara hacia un impacto regresivo del gasto público analizado. López-Acevedo y Salinas (2000) realizan un estudio de incidencia normativa personal incorporando decisiones metodológicas similares a las reseñadas. El trabajo analiza el gasto público en educación para el caso de Méjico. Los resultados de este análisis indican que el gasto en educación superior es más regresivo que el presentado por el gasto público total asignado a los hogares. Una gran proporción de los recursos públicos de este nivel se destina a estudiantes no pobres en áreas urbanas. Los 
autores proponen como solución a la regresividad observada el fomento de los mercados de crédito, y la ampliación de las ayudas financieras y becas. Demery (2000) proporciona una guía para usuarios en la que revisa cuidadosamente la metodología de los análisis de incidencia normativa, ofreciendo resultados comparables para Colombia, Costa de Marfil e Indonesia, para varios tipos de gasto público. En cuanto a los resultados, éstos muestran, para los tres países estudiados, una incidencia decididamente pro-ricos en el caso de la Educación Superior, siendo el caso de Indonesia especialmente llamativo, con un porcentaje de gasto público sobre el gasto total del $92 \%$ en la quinta quintila de gasto. Para el caso de Grecia, Antoninis y Tsakloglou (2001) llegan a la conclusión, utilizando como índice de bienestar el consumo de los hogares o de los individuos, (este último en el caso concreto de la educación superior) de que las transferencias en la educación universitaria son más regresivas que otros gastos en educación como, por ejemplo, los de formación profesional. AlSamarrai y Zaman (2002) analizan el caso de Malawi. Las cifras arrojan los siguientes resultados: los niveles de educación universitaria y secundaria favorecen claramente a las quintilas cuarta y quinta, y en una proporción de casi el doble a los hombres que a las mujeres.

\subsection{Incidencia normativa territorial}

Borraz et al. (1996), utilizando la misma metodología señalada, presentan como aportación singular un análisis territorial de la capacidad distributiva de las becas en la educación universitaria. Los resultados obtenidos muestran que dicha capacidad redistributiva varía considerablemente de unas comunidades a otras. Pérez (1996b) realiza un análisis similar que trata de medir los impactos redistributivos intra-regionales, es decir, no tiene en cuenta los efectos redistributivos entre regiones. La autora llega a conclusiones similares a las del trabajo anterior (aunque se trata de un estudio del gasto público global en educación universitaria), obteniendo que el grado de progresividad de este gasto por Comunidades Autónomas es muy dispar. En Calero (1998) se realiza además un análisis de $\beta$-convergencia, comparando los crecimientos del gasto entre los periodos inicial, 1980 y final, 1995, para cada región y $\sigma$-convergencia que estudia la evolución de la dispersión de los niveles de gasto público a lo largo del tiempo. El primero de los análisis señala los desequilibrios existentes entre regiones; el segundo, un mayor crecimiento relativo del gasto de aquellas regiones que partían de niveles más reducidos al comienzo del periodo; y como resultado final, una tendencia a la convergencia entre regiones hasta principios de los noventa, que cambia hacia una mayor dispersión a partir de esta fecha.

En definitiva, parece ser que, para el caso de España, en la década de los noventa los resultados distributivos del gasto público en educación universitaria resultan menos regresivos. Fuera de España, sin embargo, los trabajos 
realizados apuntan hacia resultados más pesimistas. Metodológicamente, estos trabajos son similares a los realizados en España. Las características de la educación en los países analizados son muy dispares, destacando como principal resultado que el gasto público en educación universitaria ha tenido un impacto tradicionalmente regresivo.

Tabla 1

Estudios sobre incidencia distributiva del gasto público en educación universitaria

\begin{tabular}{|c|c|c|c|c|}
\hline \multicolumn{5}{|c|}{ Incidencia normativa personal } \\
\hline Autor & $\begin{array}{l}\text { Ámbito } \\
\text { de } \\
\text { estudio }\end{array}$ & Tipo de gasto & $\begin{array}{c}\text { Hipótesis de } \\
\text { incidencia }\end{array}$ & Resultados de la incidencia \\
\hline $\begin{array}{l}\text { Selowsky, } \\
\text { M (1979) }\end{array}$ & Colombia & $\begin{array}{l}\text { Educación } \\
\text { Primaria, } \\
\text { Secundaria y } \\
\text { Superior }\end{array}$ & $\begin{array}{l}\text { Estudiantes por } \\
\text { niveles: } \\
\text { - áreas urbanas } \\
\text { - áreas rurales }\end{array}$ & $\begin{array}{l}\text {-Primaria y Secundaria } \\
\text { progresivas. } \\
\text { - Superior regresiva }\end{array}$ \\
\hline $\begin{array}{l}\text { Richardson, } \\
\text { S. (1985) }\end{array}$ & Australia & $\begin{array}{l}\text { Educación } \\
\text { Superior }\end{array}$ & $\begin{array}{l}\text { Estudiantes de } \\
\text { Educación } \\
\text { Superior. }\end{array}$ & $\begin{array}{l}\text {-Beneficiarios de la E. } \\
\text { Superior: estudiantes de las } \\
\text { familias mejor posicionadas } \\
\text { socialmente y mayor renta. }\end{array}$ \\
\hline $\begin{array}{l}\text { Demery } \\
(2000)\end{array}$ & $\begin{array}{l}\text { Indonesia, } \\
\text { Costa de } \\
\text { Marfil, } \\
\text { Colombia }\end{array}$ & $\begin{array}{l}\text { Educación } \\
\text { Primaria, } \\
\text { Secundaria y } \\
\text { Superior }\end{array}$ & Varias hipótesis & $\begin{array}{l}\text { - Incidencia de la E. Superior } \\
\text { decididamente pro-ricos. } \\
\text { - Mayor aprovechamiento de } \\
\text { los hombres. }\end{array}$ \\
\hline $\begin{array}{l}\text { López- } \\
\text { Acevedo y } \\
\text { Salinas } \\
(2000)\end{array}$ & Méjico & $\begin{array}{l}\text { Educación } \\
\text { Primaria, } \\
\text { Secundaria y } \\
\text { Superior }\end{array}$ & $\begin{array}{c}\text { Estudiantes por } \\
\text { niveles. }\end{array}$ & $\begin{array}{l}\text { - Mayor aprovechamiento del } \\
\text { gasto público en Educación } \\
\text { Superior por los no-pobres en } \\
\text { zonas urbanas. }\end{array}$ \\
\hline $\begin{array}{l}\text { Antoninis, } \\
\text { M., } \\
\text { Tsakloglou, } \\
\text { P. (2001) }\end{array}$ & Grecia & $\begin{array}{l}\text { Educación } \\
\text { Primaria, } \\
\text { Secundaria y } \\
\text { Superior }\end{array}$ & $\begin{array}{l}\text { Estudiantes por } \\
\quad \text { niveles } \\
\text { Estudiantes por } \\
\text { grupos de edad. }\end{array}$ & $\begin{array}{c}\text {-Primaria y Secundaria } \\
\text { progresivas } \\
\text { - Superior regresiva }\end{array}$ \\
\hline $\begin{array}{l}\text { Al- } \\
\text { Samarrai, } \\
\text { S., Zaman, } \\
\text { H. (2002) }\end{array}$ & Malawi & $\begin{array}{l}\text { Educación } \\
\text { Primaria, } \\
\text { Secundaria y } \\
\text { Superior. }\end{array}$ & $\begin{array}{c}\text { Estudiantes por } \\
\text { sexo. }\end{array}$ & $\begin{array}{l}\text {-Primaria ligeramente } \\
\text { progresiva. } \\
\text {-Secundaria y Superior } \\
\text { regresivas. } \\
\text {-Gasto muy inferior para } \\
\text { mujeres. } \\
\end{array}$ \\
\hline $\begin{array}{l}\text { Sánchez } \\
\text { Campillo } \\
(1996)\end{array}$ & $\begin{array}{l}\text { España y } \\
\text { Granada }\end{array}$ & $\begin{array}{l}\text { Educación } \\
\text { Superior }\end{array}$ & $\begin{array}{l}\text { Becarios } \\
\text { universitarios } \\
\text { según } \\
\text { titulaciones. }\end{array}$ & $\begin{array}{l}\text { - Acceso desigual de los } \\
\text { becarios por tipo de titulación } \\
\text { (preferencia por las } \\
\text { titulaciones de reducida } \\
\text { duración y mayor rendimiento } \\
\text { educativo). }\end{array}$ \\
\hline
\end{tabular}




\begin{tabular}{|c|c|c|c|c|}
\hline \multicolumn{5}{|c|}{ Incidencia normativa personal } \\
\hline Autor & $\begin{array}{c}\text { Ámbito } \\
\text { de } \\
\text { estudio }\end{array}$ & Tipo de gasto & $\begin{array}{c}\text { Hipótesis de } \\
\text { incidencia }\end{array}$ & Resultados de la incidencia \\
\hline $\begin{array}{c}\text { Mora } \\
(1996)\end{array}$ & España & $\begin{array}{l}\text { Educación } \\
\text { Universitaria }\end{array}$ & $\begin{array}{l}\text { Hogares con } \\
\text { universitarios }\end{array}$ & $\begin{array}{c}\text { - Desigualdad de } \\
\text { oportunidades en el acceso a } \\
\text { la universidad }\end{array}$ \\
\hline $\begin{array}{l}\text { Calero } \\
(1996)\end{array}$ & España & $\begin{array}{l}\text { Educación } \\
\text { Universitaria }\end{array}$ & $\begin{array}{l}\text { Hogares con } \\
\text { universitarios }\end{array}$ & $\begin{array}{c}\text { - Reducción de la } \\
\text { regresividad de } 1980 \text { a } 1990 . \\
\text { - Sistema de becas altamente } \\
\text { regresivo. }\end{array}$ \\
\hline $\begin{array}{l}\text { Pérez } \\
\text { (1996a) }\end{array}$ & España & $\begin{array}{l}\text { Educación } \\
\text { Universitaria }\end{array}$ & $\begin{array}{c}\text { Familias con } \\
\text { individuos en E. } \\
\text { Superior }\end{array}$ & $\begin{array}{c}\text { - Disminución de la } \\
\text { regresividad del gasto general } \\
\text { y del sistema de becas. } \\
\text { - Las subvenciones a } \\
\text { universidades son las más } \\
\text { regresivas. }\end{array}$ \\
\hline $\begin{array}{l}\text { Gimeno } \\
(2000)\end{array}$ & España & $\begin{array}{l}\text { Educación } \\
\text { entre otros tipos } \\
\text { de gasto }\end{array}$ & Varias hipótesis & $\begin{array}{c}\text { El gasto en Educación } \\
\text { Superior parece resultar ya } \\
\text { levemente progresivo, si bien } \\
\text { cerca de la proporcionalidad. }\end{array}$ \\
\hline $\begin{array}{l}\text { Calero } \\
(2002)\end{array}$ & España & $\begin{array}{l}\text { Educación } \\
\text { entre otros tipos } \\
\text { de gasto }\end{array}$ & Varias hipótesis & $\begin{array}{c}\text { - Las clases medias no son } \\
\text { las grandes beneficiadas del } \\
\text { gasto. } \\
\text { - Grandes desigualdades } \\
\text { entre grupos. }\end{array}$ \\
\hline \multicolumn{5}{|c|}{ Incidencia normativa territorial } \\
\hline $\begin{array}{l}\text { Pérez } \\
\text { (1996b) }\end{array}$ & España & $\begin{array}{l}\text { Educación } \\
\text { Universitaria }\end{array}$ & $\begin{array}{l}\text { Familias con } \\
\text { individuos en E. } \\
\text { Superior por } \\
\text { CC.AA. }\end{array}$ & $\begin{array}{l}\text { - Grado de progresividad muy } \\
\text { diferente por CC.AA. }\end{array}$ \\
\hline $\begin{array}{l}\text { Borraz et al. } \\
\quad(1996)\end{array}$ & España & $\begin{array}{l}\text { Becas en } \\
\text { educación } \\
\text { Universitaria }\end{array}$ & $\begin{array}{c}\text { Hogares con } \\
\text { estudiantes } \\
\text { universitarios por } \\
\text { CC.AA. }\end{array}$ & $\begin{array}{l}\text { - Capacidad redistributiva } \\
\text { muy desigual por regiones. } \\
\text { - Peores resultados para las } \\
\text { comunidades más ricas. }\end{array}$ \\
\hline $\begin{array}{l}\text { Calero } \\
(1998)\end{array}$ & España & $\begin{array}{l}\text { Educación } \\
\text { Superior }\end{array}$ & $\begin{array}{l}\text { Hogares con } \\
\text { estudiantes } \\
\text { universitarios }\end{array}$ & $\begin{array}{l}\text { - Incremento de la incidencia } \\
\text { en las decilas medias. } \\
\text { - Reducción de las diferencias } \\
\text { entre CC.AA. }\end{array}$ \\
\hline
\end{tabular}




\section{ANÁLISIS EMPÍRICO DE LA INCIDENCIA DISTRIBUTIVA DEL GASTO EN EDUCACIÓN UNIVERSITARIA EN ESPAÑA: PRINCIPALES DECISIONES METODOLÓGICAS}

El análisis empírico que se aporta en este epígrafe aplica los criterios metodológicos tradicionales en incidencia normativa ${ }^{6}$. Como aportaciones específicas más reseñables, cabe citar las siguientes:

- Utilización de nuevas bases de datos: El estudio se realiza para los años 2000 y 2004, utilizando el Panel de Hogares de la Unión Europea (PHOGUE, en adelante) y la Encuesta de Condiciones de $\mathrm{Vida}^{7}$ (ECV, en adelante), respectivamente. Con ello, se abre la posibilidad de extraer conclusiones acerca de la evolución de la incidencia del gasto público en educación universitaria en nuestro país. La elección de estos dos periodos está ligada a las fuentes de datos de las que se dispone para realizar el estudio aplicado. La inmensa mayoría de estudios ha hecho uso de las Encuestas Básicas de Presupuestos Familiares (EBPF, en adelante) para los años 1980-81 y 1990-91. La falta de sucesivas publicaciones dejó estas bases de datos obsoletas. La publicación del PHOGUE (1994-2001) y posteriormente, de la ECV (2004-2005) ha permitido retomar este tipo de análisis, ya que contienen la información necesaria para ello ${ }^{8}$. Por tanto, el uso de la muestra ampliada del Panel de Hogares de la Unión Europea para el año 2000 y la Encuesta de Condiciones de Vida para el año 2004 permiten actualizar los estudios de incidencia normativa, así como dotar a nuestro análisis de una dimensión temporal. Este hecho abre la posibilidad de contrastar si existen diferencias significativas en los resultados cuando se aplican bases de datos distintas. Sin embargo, el hecho de utilizar dos encuestas diferentes, cuyas muestras y diseños muestrales no son iguales, hace que estas comparaciones deban realizarse con ciertas cautelas y además, hace necesaria una minuciosa labor de preparación de los datos y de homogenización de variables para que los resultados sean comparables. (En el Anexo se ofrece la

\footnotetext{
${ }^{6}$ Para una revisión de las fases metodológicas tradicionales del enfoque de incidencia normativa, véanse, entre otros, De Pablos y Valiño (2000), Calero (1996).

7 Los años disponibles en la Encuesta de Condiciones de Vida se refieren a los años 2004 y 2005. Hemos decidido escoger el año 2004 debido a que buena parte de las variables necesarias para nuestro análisis no están aún procesadas.

8 Aunque se ha estudiado la posibilidad de incluir en el estudio la Encuesta Continua de Presupuestos Familiares (ECPF), finalmente se ha tomado la decisión de no utilizarla para el análisis de la incidencia, puesto que no cuenta con la información necesaria para la identificación exacta de los usuarios, lo que supondría la necesidad de una estimación indirecta de los mismos. Debido a esta importante limitación, y a pesar del interés que tiene utilizar una base de datos con información sobre los gastos realizados por el hogar, se ha optado por no incluirla en este análisis de incidencia a corto plazo.
} 
Tabla 1, que resume las principales características de cada base de datos, así como las ventajas y limitaciones de cada una de ellas para realizar análisis de incidencia normativa).

- También es destacable, la realización de un doble análisis de incidencia normativa del gasto público en educación universitaria: a nivel nacional y a nivel regional. El primero de ellos es el normalmente aplicado en la mayoría de trabajos. Sin embargo, el hecho de que este gasto esté altamente descentralizado hacia las CCAA desde 1996, hace indispensable la realización de un análisis de corte regional, que explore las diferencias, tanto del impacto distributivo que este gasto genera dentro de cada una de nuestras comunidades (incidencia intraregional), como las diferencias en la importancia relativa de este gasto en cada una de ellas (incidencia inter-regional). Las dos bases de datos que se han empleado cuentan con información detallada y representativa a nivel regional, lo que posibilita este estudio desagregado. Con ello, se pretende contrastar si los resultados a nivel nacional pueden ocultar realidades diferentes a nivel regional.

- La unidad de análisis seleccionada para el estudio empírico es el hogar, dado que se trata de un estudio a corto plazo. La implicación inmediata de esta elección es la necesidad de aplicar escalas de equivalencia, para que las rentas de los hogares que sean diferentes en tamaño y composición sean comparables. En este sentido, y al no existir un acuerdo generalizado sobre cuál es la mejor escala de equivalencia (Ursicino, 1996), la mayoría de estudios de incidencia tradicionales se decantan por el uso de la escala de la OCDE, mientras que en los más recientes se ha propuesto fundamentalmente la escala paramétrica de Buhmann et al. (1988). En este trabajo se ha optado por realizar cuatro estimaciones diferentes: una para cada una de las tres escalas más comunes (OCDE, OCDE modificada, y escala de Buhmann et al. (1988) con parámetro igual a $1 / 2$ ) y una cuarta estimación para una submuestra en la que el sustentador principal tiene entre 45 y 65 (escala OCDE). El objetivo de llevar a cabo estas cuatro estimaciones es el de contrastar la sensibilidad de resultados a la escala utilizada, y sobre todo, para comprobar si el uso de diferentes escalas proporciona resultados contradictorios.

- Por lo que se refiere a los criterios a aplicar en la imputación del gasto, la opción normalmente tomada consiste en asignar a cada beneficiario el gasto público total entre el número de alumnos matriculados en ese nivel educativo. Esta imputación tan homogénea oculta la realidad de la distribución de este gasto, la cual puede ser muy diferente entre regiones, entre las ramas educativas (ramas de Humanidades, Técnicas, Sociales y Jurídicas, Sanitarias o Experimentales) y entre las elecciones de estas rama educativa que, de forma diferenciada, realizan hombres y mujeres. Por ello, en este trabajo se ha decidido depurar la imputación realizada, aplicando ajustes por movilidad de 
alumnos entre regiones, por ramas educativas y por sexo. Estos ajustes ${ }^{9}$ se han llevado a cabo según la información que se recoge en la Tabla 2 del Anexo.

- En relación a los indicadores que midan el impacto redistributivo del gasto público en educación, se utilizan dos aproximaciones distintas:

- A través del cálculo tradicional de incidencia, esto es, analizando el peso relativo que supone el gasto público en educación sobre la renta media por grupos de renta (decilas) o sobre la renta media total de la población. Los primeros indicadores de incidencia recogen la proporción que el gasto público medio en educación universitaria recibido por cada decila supone respecto a la renta media disponible de esa misma decila. Es un índice muy utilizado, pero con limitaciones importantes dado que el denominador sería la renta media de cada decila y, por tanto, es bastante inferior en las decilas más bajas. Este hecho puede hacernos creer que, si las decilas bajas presentan porcentajes de incidencia altos, es porque el gasto público en educación universitaria es elevado, lo cual no tiene por qué ser del todo cierto. Insistimos en que éste es un índice de importancia relativa. Con el objetivo de corregir el hecho de que el indicador anterior pueda reflejar cifras altas de incidencia en las primeras decilas exclusivamente porque las rentas de estas decilas son bajas, se ha aplicado un segundo indicador de incidencia, el cual mide la importancia relativa de la subvención media recibida por cada decila con respecto a la renta media del total de la población

- A través del cálculo de índices sintéticos que permitan medir el grado de progresividad y redistribución del gasto en educación universitaria. Los índices de importancia relativa del gasto con respecto a la renta se aproximan al cálculo de la incidencia de una forma que puede ser considerada demasiado simple. Por ello, adicionalmente se ha calculado una serie de indicadores de progresividad y redistribución habituales en este tipo de literatura. En concreto, se propone el cálculo del índice de Kakwani y el de Reynolds-Smolensky.

Para medir la progresividad del gasto público analizado se utiliza el índice de Kakwani (1977) (K), con las siguientes formulaciones según se trate de un gasto público en especie o en efectivo, respectivamente:

$$
\mathrm{K}_{\mathrm{s}}=\mathrm{G}\left(\mathrm{x}_{\mathrm{d}}\right)-\mathrm{G}\left(\mathrm{s}, \mathrm{x}_{\mathrm{d}}\right) \quad \mathrm{K}_{\mathrm{b}}=\mathrm{G}\left(\mathrm{x}_{\mathrm{i}}\right)-\mathrm{G}\left(\mathrm{b}, \mathrm{x}_{\mathrm{i}}\right)
$$

\footnotetext{
${ }^{9}$ Ministerio de Educación (varios años) "Las cifras de la Educación en España: Estadísticas e Indicadores", en los cuadros que recogen la relación entre el domicilio familiar del alumnado en Educación Universitaria y la ubicación del centro en el que cursan los estudios y en los cuadros que recogen la distribución porcentual del alumnado y porcentaje de mujeres por área de estudio.
} 
Donde:

- $\mathrm{G}\left(\mathrm{x}_{\mathrm{d}}\right)=$ índice de Gini de la distribución de la renta disponible.

- $\mathrm{G}\left(\mathrm{s}, \mathrm{x}_{\mathrm{d}}\right)=$ índice pseudo-Gini de concentración del gasto público en especie (subvención).

- $\mathrm{G}\left(\mathrm{x}_{\mathrm{i}}\right)=$ índice de Gini de la distribución de la renta inicial.

- $\mathrm{G}\left(\mathrm{b}, \mathrm{x}_{\mathrm{i}}\right)$ = índice pseudo-Gini de concentración del gasto público en efectivo (becas).

- $\mathrm{s}$ = gasto en especie (subvención, tal como se verá más adelante).

- $b=$ gasto en efectivo (becas, tal como se comprobará más adelante).

El índice de Kakwani (1977) mide la progresividad con respecto a una distribución de renta inicial de un determinado gasto. Los índices pseudo-Gini de concentración de los gastos pueden ser negativos, lo que indicaría una progresividad absoluta (es decir, un trazado de la curva de Lorenz por encima de la diagonal principal). El índice de Kakwani indica cuál es la progresividad relativa, comparada con respecto a la distribución de renta inicial ${ }^{10}$. Para que un gasto público sea caracterizado como progresivo, es necesario que su distribución sea menos desigual que la distribución de la renta antes del gasto. En este caso el índice será positivo, mientras que en caso de regresividad, su valor será negativo. El rango de variación del índice de Kakwani está entre -1 y 2 , siendo la progresividad máxima cuando $\mathrm{K}=2$. El índice de Kakwani será igual a 2 cuando el valor del índice de Gini de la renta inicial sea el máximo posible (lo que indicaría que un único individuo tiene toda la renta inicial) y el índice de concentración del gasto sea igual a -1 , reflejando una situación en la que el individuo más pobre recibe todo el gasto público.

El efecto redistributivo de un gasto depende tanto de la progresividad formal como de la cuantía que supone el gasto en relación con la renta inicial. Para medir la capacidad redistributiva del gasto público $j$, en efectivo o en especie, se utilizan el índice de Reynolds-Smolensky (1977) (RS) y el de ReynoldsSmolensky reconsiderado $\left(\mathrm{RS}^{*}\right)$, con las siguientes formulaciones, respectivamente:

$$
\begin{aligned}
& R S_{j}=G(x)-G(y, x) \\
& R S_{j}{ }^{*}=G(x)-G(y)
\end{aligned}
$$

Donde:

- $\mathrm{j}=\mathrm{s}, \mathrm{b}$ (subvención o gasto en especie, becas o gasto en efectivo, respectivamente).

\footnotetext{
${ }^{10}$ Para los gastos en especie, se considera como renta antes del gasto la renta disponible $-\mathrm{G}\left(\mathrm{x}_{\mathrm{d}}\right)$-, mientras que para los gastos en efectivo, se utilizará la renta inicial - $\mathrm{G}\left(\mathrm{x}_{\mathrm{i}}\right)$-.
} 
- $\mathrm{G}(\mathrm{y}, \mathrm{x})$ = índice de Gini de la renta posterior al gasto, calculado con la ordenación proporcionada por la renta inicial.

- $\mathrm{G}(\mathrm{y})$ = índice de Gini de la renta posterior al gasto, calculado con la ordenación proporcionada por la renta final.

El RS o RS ${ }^{*}$ es positivo si el índice Gini de la renta antes del gasto es mayor que el índice de Gini de la renta después del gasto, lo que indica que el gasto es redistributivo. Por el contrario, si es nulo indica que el gasto no tiene efectos redistributivos sobre la renta. Por último, si es negativo, muestra un efecto redistributivo regresivo del gasto sobre la distribución de la renta. El uso del $\mathrm{RS}^{*}$ de forma complementaria al RS es habitual puesto que evita las posibles reordenaciones (re-rankings) de los hogares que el gasto produce en términos de renta, debidas a la ruptura del principio de equidad horizontal. La diferencia entre RS y RS* está provocada por estas posibles reordenaciones, de tal manera que se pueden expresar como:

$$
\mathrm{RS}^{*}=\mathrm{RS}-\mathrm{R}
$$

Donde $\mathrm{R}$ = reordenación de rentas que un gasto público provoca.

\section{PRINCIPALES RESULTADOS DE INCIDENCIA NORMATIVA DE LA EDUCACIÓN UNIVERSITARIA A NIVEL NACIONAL}

Los resultados de incidencia normativa se ofrecen en dos epígrafes, atendiendo a las dos aproximaciones descritas en el apartado anterior.

\section{1. Índices de incidencia de la subvención en educación universitaria: por grupos de renta y respecto a la renta media total}

En la Tabla 2 se ofrecen los indicadores de incidencia por grupos de renta, en este caso, decilas. De estos resultados se puede destacar, que este primer indicador de incidencia muestra, en general, para todas las correcciones realizadas y para las dos encuestas utilizadas, un mayor impacto en la primera decila. Asimismo, se observa, sea cual sea la escala de equivalencia escogida, que la incidencia del gasto es más baja a medida que aumenta la renta. Sin embargo, la dimensión de las cifras varía de forma considerable dependiendo de la escala de equivalencia utilizada y de la base de datos. Así, la corrección por la edad del sustentador principal (OCDE SP) revela mayores valores de este indicador para todas las decilas, especialmente para la primera $(15,33 \%$ en el PHOGUE, $19,26 \%$ para la ECV). Asimismo la incidencia media del gasto público en educación universitaria es importante con independencia de la base de datos y de la decisión metodológica adoptada, siempre por encima del 2,5\%, si bien en el año 2000 los resultados alcanzados a partir del PHOGHE sitúan este porcentaje por encima del 3\%. Estos resultados ponen de manifiesto un 
aumento de incidencia importante en comparación con estudios anteriores (Calero, 1996).

Tabla 2

Índices de incidencia por grupos (decilas) de renta disponible. España, 2000 y 2004

\begin{tabular}{|c|c|c|c|c|}
\hline PHOGUE & OCDE & OCDE SP & OCDEMOD & BUHMANN \\
\hline 1 & $9,33 \%$ & $15,33 \%$ & $9,26 \%$ & $10,26 \%$ \\
\hline 2 & $3,45 \%$ & $9,08 \%$ & $3,48 \%$ & $3,96 \%$ \\
\hline 3 & $5,19 \%$ & $11,78 \%$ & $5,32 \%$ & $5,87 \%$ \\
\hline 4 & $3,76 \%$ & $8,45 \%$ & $3,86 \%$ & $4,32 \%$ \\
\hline 5 & $3,00 \%$ & $5,69 \%$ & $3,04 \%$ & $3,22 \%$ \\
\hline 6 & $3,31 \%$ & $6,46 \%$ & $3,35 \%$ & $3,60 \%$ \\
\hline 7 & $2,78 \%$ & $4,87 \%$ & $2,86 \%$ & $3,16 \%$ \\
\hline 8 & $2,64 \%$ & $4,49 \%$ & $2,67 \%$ & $2,78 \%$ \\
\hline 9 & $2,48 \%$ & $3,90 \%$ & $2,53 \%$ & $2,67 \%$ \\
\hline 10 & $1,98 \%$ & $3,01 \%$ & $2,03 \%$ & $2,22 \%$ \\
\hline Media & $\mathbf{3 , 0 1 \%}$ & $\mathbf{5 , 6 5 \%}$ & $\mathbf{3 , 0 6} \%$ & $\mathbf{3 , 3 1 \%}$ \\
\hline
\end{tabular}

\begin{tabular}{|c|c|c|c|c|}
\hline ECV & OCDE & OCDE SP & OCDEMOD & BUHMANN \\
\hline 1 & $8,13 \%$ & $19,26 \%$ & $8,28 \%$ & $9,19 \%$ \\
\hline 2 & $4,04 \%$ & $10,00 \%$ & $4,15 \%$ & $4,64 \%$ \\
\hline 3 & $2,53 \%$ & $6,19 \%$ & $2,60 \%$ & $2,85 \%$ \\
\hline 4 & $2,86 \%$ & $5,16 \%$ & $2,93 \%$ & $3,17 \%$ \\
\hline 5 & $2,77 \%$ & $4,96 \%$ & $2,79 \%$ & $2,98 \%$ \\
\hline 6 & $2,35 \%$ & $3,89 \%$ & $2,36 \%$ & $2,50 \%$ \\
\hline 7 & $1,86 \%$ & $3,29 \%$ & $1,88 \%$ & $1,97 \%$ \\
\hline 8 & $2,09 \%$ & $3,43 \%$ & $2,12 \%$ & $2,21 \%$ \\
\hline 9 & $1,77 \%$ & $2,76 \%$ & $1,78 \%$ & $1,83 \%$ \\
\hline 10 & $1,61 \%$ & $1,99 \%$ & $1,60 \%$ & $1,62 \%$ \\
\hline Media & $\mathbf{2 , 3 3 \%}$ & $\mathbf{4 , 2 0 \%}$ & $\mathbf{2 , 3 7 \%}$ & $\mathbf{2 , 5 0 \%}$ \\
\hline
\end{tabular}

Fuente: Elaboración propia a partir de PHOGUE, 2000 y ECV, 2004

Los resultados cambian notablemente en relación a los comentados anteriormente si se compara la subvención recibida en cada decila con su respectiva renta media (Tabla 3), puesto que en este caso realmente muestran la importancia de las cuantías de gasto recibidas por cada decila. Así, con el PHOGUE se aprecia, para casi todos los casos analizados, una inversión de la relación subvención-renta, siendo las decilas más altas las que mayor porcentaje presentan en este indicador. De nuevo, los valores son más elevados con la 
corrección por la edad de sustentador principal (OCDE SP), así como con la escala de Buhmann et al. (1988). Para el caso de la ECV, hay que señalar como resultado relevante una casi equidistribución de la subvención por decilas para todas las correcciones (cercanas al 2\%, $4 \%$ en el caso de la corrección por edad del sustentador). Esto implica que la cuantía de las subvenciones en educación universitaria presenta valores más o menos similares en todas las decilas de renta. Únicamente hay que destacar que en la última decila se observa un valor superior al $4 \%$ para todas las correcciones, lo que supone un mayor gasto en el grupo de renta más elevada. La incidencia media del gasto universitario lógicamente es la misma que con el índice anterior.

Tabla 3

Índices de incidencia respecto a la renta media total, por decilas de renta disponible.

España, 2000 y 2004.

\begin{tabular}{|c|c|c|c|c|}
\hline & OCDE & OCDE SP & OCDEMOD & BUHMANN \\
\hline 1 & $2,55 \%$ & $4,25 \%$ & $2,57 \%$ & $2,74 \%$ \\
\hline 2 & $1,61 \%$ & $4,39 \%$ & $1,64 \%$ & $1,79 \%$ \\
\hline 3 & $3,03 \%$ & $7,08 \%$ & $3,08 \%$ & $3,30 \%$ \\
\hline 4 & $2,57 \%$ & $5,95 \%$ & $2,65 \%$ & $2,92 \%$ \\
\hline 5 & $2,36 \%$ & $4,68 \%$ & $2,40 \%$ & $2,53 \%$ \\
\hline 6 & $3,02 \%$ & $6,10 \%$ & $3,07 \%$ & $3,29 \%$ \\
\hline 7 & $2,94 \%$ & $5,15 \%$ & $3,03 \%$ & $3,36 \%$ \\
\hline 8 & $3,29 \%$ & $5,48 \%$ & $3,32 \%$ & $3,50 \%$ \\
\hline 9 & $3,85 \%$ & $5,84 \%$ & $3,90 \%$ & $4,16 \%$ \\
\hline 10 & $4,84 \%$ & $7,20 \%$ & $4,94 \%$ & $5,47 \%$ \\
\hline Media & $\mathbf{3 , 0 1} \%$ & $\mathbf{5 , 6 5 \%}$ & $\mathbf{3 , 0 6} \%$ & $\mathbf{3 , 3 1 \%}$ \\
\hline
\end{tabular}

\begin{tabular}{|c|c|c|c|c|}
\hline ECV & OCDE & OCDE SP & OCDEMOD & BUHMANN \\
\hline 1 & $2,33 \%$ & $5,55 \%$ & $2,39 \%$ & $2,58 \%$ \\
\hline 2 & $1,93 \%$ & $4,97 \%$ & $1,98 \%$ & $2,16 \%$ \\
\hline 3 & $1,51 \%$ & $3,86 \%$ & $1,56 \%$ & $1,69 \%$ \\
\hline 4 & $2,04 \%$ & $3,81 \%$ & $2,10 \%$ & $2,26 \%$ \\
\hline 5 & $2,29 \%$ & $4,17 \%$ & $2,33 \%$ & $2,49 \%$ \\
\hline 6 & $2,22 \%$ & $3,70 \%$ & $2,25 \%$ & $2,41 \%$ \\
\hline 7 & $2,01 \%$ & $3,52 \%$ & $2,05 \%$ & $2,19 \%$ \\
\hline 8 & $2,62 \%$ & $4,24 \%$ & $2,67 \%$ & $2,80 \%$ \\
\hline 9 & $2,66 \%$ & $4,08 \%$ & $2,67 \%$ & $2,76 \%$ \\
\hline 10 & $3,73 \%$ & $4,53 \%$ & $3,66 \%$ & $3,67 \%$ \\
\hline Media & $\mathbf{2 , 3 3} \%$ & $\mathbf{4 , 2 0} \%$ & $\mathbf{2 , 3 7 \%}$ & $\mathbf{2 , 5 0 \%}$ \\
\hline
\end{tabular}

Fuente: Elaboración propia a partir de PHOGUE, 2000 y ECV, 2004 
Si se comparan los valores de los índices de incidencia por grupos de renta con los índices de incidencia calculados sobre la renta media total, tanto para la ECV como para el PHOGUE, a través de una representación gráfica (Gráfico $1^{11}$ ), se comprueba que existe un punto de cruce entre ambos en la séptima decila. Hasta ese punto, la incidencia medida como porcentaje de la renta media de cada decila es superior a la incidencia medida respecto a la renta media total. Esto indica que, para las decilas bajas y medias, la subvención por educación universitaria tiene un peso relativamente elevado respecto a su renta media, pero si relativizamos por la misma renta (renta media total) la situación se invierte y el valor del indicador de incidencia es mayor para las rentas más altas. Mientras que con el primer indicador (incidencia respecto a la renta media de cada decila) se observa que la incidencia disminuye a medida que aumentan las decilas, con el segundo (incidencia respecto a la renta media total), la relación es la contraria, es decir, la incidencia aumenta ligeramente con las decilas de renta.

\section{Gráfico 1.-}

Índices de incidencia por decilas de renta disponible, OCDE. España, 2000 y 2004
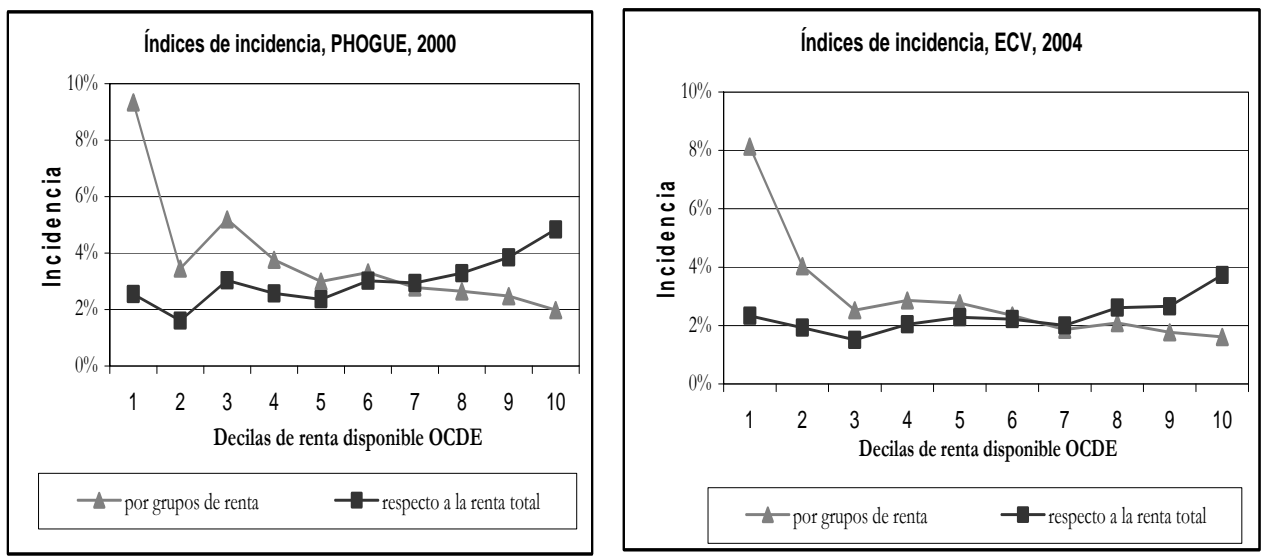

Fuente: Elaboración propia a partir de PHOGUE, 2000 y ECV, 2004.

\section{2. Índices de progresividad y redistribución}

Como se comentó en el apartado 3, esta segunda aproximación a la incidencia del gasto nos ofrece resultados adicionales para un conocimiento más completo del impacto distributivo real del gasto público, midiendo el grado de

${ }^{11}$ Aunque el Gráfico 1 se ofrece para la escala de la OCDE, se comprueba que el resultado es similar para el resto de escalas. 
progresividad y redistribución que permite alcanzar el gasto en educación universitaria.

\subsection{1.Índices de progresividad del gasto público en educación universitaria: índice de Kakwani}

A través del índice de Kakwani se analiza la progresividad relativa de la subvención a la educación universitaria $\left(\mathrm{K}_{\mathrm{s}}\right)$, así como de las becas $\left(\mathrm{K}_{\mathrm{b}}\right)($ Tabla 4). En el primer caso, y al tratarse de un gasto en especie, es esperable que el nivel de progresividad sea inferior al de las prestaciones en efectivo (Calero, 2002). Además, se está analizando un tipo de gasto que tradicionalmente ha presentado cierta regresividad relativa. Los resultados obtenidos para el año 2000 (PHOGUE) muestran cierta progresividad de este tipo de gasto, que se sitúa en torno al 0,18 con las escalas de la OCDE y OCDE modificada, y que alcanza un 0,27 en el caso de la corrección por edad del sustentador. Cuando utilizamos la escala de Buhmann et al. (1988), el índice de Kakwani disminuye considerablemente para ambas bases de datos $\left(\mathrm{K}_{\mathrm{sPHOGUE}}=0,0999 ; \mathrm{K}_{\mathrm{sECV}}=\right.$ 0,1495). Sin embargo, los resultados en 2004 (ECV) son más favorables, en el sentido de que los valores del índice son significativamente más elevados, aunque es necesario tomar con cautelas este resultado en términos de evolución, debido a que se trata de diferentes bases de datos. En cualquier caso, y sea cual sea la decisión metodológica adoptada, el valor de este indicador, en general, resulta significativamente superior al obtenido por Calero (2001) para este tipo de gasto $\left(K_{\mathrm{s}}=0,0877\right)$ en 1995 .

En cuanto al gasto en efectivo o becas entregadas a los estudiantes, únicamente se ha analizado la progresividad de este tipo de gasto para el año 2004, con datos de la ECV. Ésta es la única base de datos que contiene la información necesaria para poder aproximarse al estudio del impacto distributivo de las becas ${ }^{12}$. El índice de progresividad $\left(\mathrm{K}_{\mathrm{b}}\right)$ es realmente elevado sea cual sea la escala de equivalencia seleccionada: 0,65293 ${ }_{\mathrm{OCDE}}$; 0,65353 OCDESP; $0,63308_{\text {OCDEMOD; }}$ 0,53928 BUHMANN. Dadas las características de este tipo de gasto, es esperable que los gastos en efectivo supongan una mayor progresividad que los gastos en especie, como queda comprobado en nuestro caso.

4.2.2. Índice de redistribución del gasto público universitario: Índice de Reynolds-Smolensky

Los resultados en cuanto a la redistribución que permiten alcanzar este tipo de gasto son los siguientes (recogidos en Tabla 4): a excepción de un único

${ }^{12}$ El PHOGUE no puede utilizarse para medir la incidencia de las becas, ya que ni el número de becarios ni el importe de las becas resulta ser representativo a nivel poblacional. 
caso, todos los valores de estos índices son positivos, lo que indica que se trata de un gasto redistributivo progresivo. Sin embargo, los valores son realmente pequeños lo que indica impactos redistributivos realmente bajos, lo cual se atribuye a la pequeña cuantía que supone este gasto respecto a la renta total. Por otra parte, los valores del $\mathrm{RS}_{\mathrm{s}}$ son superiores que los del $\mathrm{RS}_{\mathrm{s}}{ }^{*}$, puesto que $\mathrm{RS}_{\mathrm{s}}$ incorpora el efecto provocado por la reordenación $\left(\mathrm{R}_{\mathrm{s}}\right)$.

Los resultados muestran cierta sensibilidad según las bases de datos y escalas de equivalencia aplicadas. En concreto, el PHOGUE arroja resultados distributivos ligeramente mayores que la $\mathrm{ECV}$, a excepción de los obtenidos con la escala de Buhmann et al. (1988). Además, en ambos casos y, en cuanto al $\mathrm{RS}_{\mathrm{s}}$, la corrección por la edad del sustentador principal es la que proporciona un mayor valor de este índice (alrededor de 0,01), seguida de la escala de Buhmann et al. (1988) (0,0032), mientras que las escalas de la OCDE muestran valores cercanos a 0,005 . Estos valores son inferiores a los obtenidos por Calero (2001) para este mismo indicador, aunque en su caso se estudian todos los niveles educativos. Si tenemos en cuenta el $\mathrm{RS}_{\mathrm{s}}{ }^{*}$, es decir, excluimos el efecto provocado por los "re-rankings", esto es, las posibles reordenaciones de los hogares que el gasto produce en términos de renta, entonces los valores disminuyen, aproximándose a 0,001 .

Los comentarios realizados para la subvención en educación universitaria respecto al cambio de los resultados en función de las escalas aplicadas en los índices de redistribución son extrapolables para el caso de las becas $\left(\mathrm{RS}_{\mathrm{b}}, \mathrm{RS}_{\mathrm{b}}{ }^{*}\right.$ o $R_{b}$, respectivamente). Sin embargo, los valores de la redistribución en el caso de las transferencias en efectivo son mayores, las becas en el sistema de enseñanza universitaria provocan cierta redistribución de la renta, produciendo además una reordenación de los hogares, siendo los valores de $\mathrm{R}_{\mathrm{b}}$ superiores a 0,003 .

Tabla 4.

Índices de progresividad y redistribución: Kakwani (K), Reynolds-Smolensky (RS), Reynolds-Smolensky reformulado (RS*) y Reordenación (R). España, 2000 y 2004

\begin{tabular}{|c|c|c|c|c|}
\hline PHOGUE & OCDE & OCDE SP & OCDEMOD & BUHMANN \\
\hline $\mathrm{K}_{\mathrm{s}}$ & 0,19139 & 0,27162 & 0,17158 & 0,09997 \\
\hline $\mathrm{RS}_{\mathrm{s}}$ & 0,00558 & 0,01453 & 0,00509 & 0,00320 \\
\hline $\mathrm{RS}_{\mathrm{s}}{ }^{*}$ & 0,00275 & 0,00994 & 0,00226 & 0,00027 \\
\hline $\mathrm{R}_{\mathrm{s}}$ & 0,00283 & 0,00459 & 0,00284 & 0,00293 \\
\hline
\end{tabular}




\begin{tabular}{|c|c|c|c|c|}
\hline ECV & OCDE & OCDE SP & OCDEMOD & BUHMANN \\
\hline $\mathrm{K}_{\mathrm{s}}$ & 0,20656 & 0,32245 & 0,19715 & 0,14959 \\
\hline $\mathrm{K}_{\mathrm{b}}$ & 0,65293 & 0,65353 & 0,63308 & 0,53928 \\
\hline $\mathrm{RS}_{\mathrm{s}}$ & 0,00471 & 0,01299 & 0,00455 & 0,00367 \\
\hline $\mathrm{RS}_{\mathrm{b}}$ & 0,00594 & 0,01567 & 0,00579 & 0,00481 \\
\hline $\mathrm{RS}_{\mathrm{s}}{ }^{*}$ & 0,00205 & 0,00848 & 0,00182 & 0,00074 \\
\hline $\mathrm{RS}_{\mathrm{b}}{ }^{*}$ & 0,00242 & 0,00966 & 0,00216 & 0,00092 \\
\hline $\mathrm{R}_{\mathrm{s}}$ & 0,00266 & 0,00452 & 0,00273 & 0,00293 \\
\hline $\mathrm{R}_{\mathrm{b}}$ & 0,00352 & 0,00601 & 0,00362 & 0,00389 \\
\hline
\end{tabular}

Fuente: Elaboración propia a partir de PHOGUE, 2000 y ECV, 2004

\section{INCIDENCIA NORMATIVA DEL GASTO EN EDUCACIÓN UNIVERSITARIA A NIVEL REGIONAL}

El gasto público en educación universitaria es competencia de las Comunidades Autónomas desde mediados de la década de los noventa. El hecho de que este gasto esté altamente descentralizado hace indispensable la realización de un análisis de corte regional, que explore las diferencias, tanto del impacto distributivo que este gasto genera dentro de cada una de nuestras comunidades (incidencia intra-regional), como la incidencia que causa entre ellas (incidencia inter-regional). Tanto el PHOGUE 2000 como la ECV 2004, cuentan con información detallada y representativa a nivel regional, lo que posibilita este estudio desagregado. Con ello, se pretende contrastar si los resultados a nivel nacional pueden ocultar realidades diferentes a nivel regional.

\subsection{Incidencia inter-regional ${ }^{13}$}

A nivel territorial ${ }^{14}$, lo primero que interesa poner de manifiesto es si existen diferencias en la incidencia a nivel regional del gasto público en educación - y si las diferentes regiones siguen las pautas de incidencia observadas a nivel nacional -, esto es, cómo se benefician del gasto las diferentes regiones. En este caso podemos comparar la subvención media recibida por cada región, con la renta media disponible de cada región. Sin embargo encontramos, de nuevo, con el problema que apuntábamos anteriormente. Pueden aparecer cifras de incidencia "ficticiamente altas" en regiones determinadas cuyo nivel de renta media disponible es bajo. Por ello,

${ }^{13}$ Recordamos que seguimos los mismos criterios metodológicos en cuanto a la imputación del gasto. Por tanto, el gasto imputado es el ajustado por ramas, movilidad y género.

${ }^{14}$ En general, se ha replicado la metodología aplicada a nivel nacional, si bien únicamente se ofrecen los resultados alcanzados con la escala de equivalencia OCDE, debido a que el uso de diferentes escalas no modifica la dirección de los resultados. 
nos hemos inclinado por aplicar directamente el ratio de incidencia que toma como numerador la subvención media de cada región, pero cuyo denominador contempla la renta media disponible nacional.

Los resultados recogidos en la Tabla 5 ponen de manifiesto, cualquiera que sea la base de datos tomada, disparidades de importancia de la incidencia del gasto considerado en las diferentes regiones. Por ejemplo: tomando el PHOGUE y la escala de equivalencia de la OCDE, el rango de incidencia regional oscila entre el 4,25\% de Madrid y el 1,88\% de Baleares. La incidencia media es de $2,91 \%$. Las regiones que presentan una mayor incidencia son Madrid (4,25\%), Castilla León (3,19\%). La Rioja (3,24\%), País Vasco (3,31\%) y Cataluña $(3,19 \%)$. Por contra Castilla la Mancha $(1,98 \%)$ y Baleares $(1,88 \%)$ son las que tienen menor incidencia, para el año $2000{ }^{15}$.

Los resultados obtenidos en la ECV 2004 son bastante diferentes. En general, la incidencia medida como porcentaje de la renta media disponible a nivel nacional en 2004 resulta menor, hecho que puede deberse al incremento observado en los niveles de renta. Además, algunas regiones presentan resultados muy distintos a los obtenidos en 2000. Por poner un ejemplo, Madrid o Cantabria registran índices de incidencia mucho más bajos. En este sentido, es necesario señalar algunos problemas de falta de respuesta que se han observado en la ECV, centrados fundamentalmente en estas dos regiones, lo que ha de tenerse en cuenta a la hora de interpretar los resultados.

Los resultados obtenidos con la ECV, aplicando la escala de equivalencia de la OCDE, muestran una incidencia media del 2,34\%. Destacan con incidencias especialmente elevadas Navarra $(4,40 \%)$, la Comunidad Valencia $(3,26 \%)$, Aragón (2,95\%) o La Rioja (2,74\%). Por el contrario, vuelven a destacar por su baja incidencia Baleares $(1,88 \%)$, Castilla la Mancha $(1,92 \%)$ a las que cabe añadir el caso de Extremadura (1,88\%) y Andalucía (1,73\%).

A pesar de las divergencias apuntadas en los resultados de 2004 respecto de 2000 , lo cierto es que ambas fuentes coinciden en presentar una disparidad entre regiones muy destacable en los índices de incidencia del gasto público en educación universitaria.

\footnotetext{
${ }^{15}$ Se ofrece una visión panorámica de la educación superior a finales de la década de los noventa, en López Afonso casado, J.M. M. Hernández López (1998).
} 
Tabla 5.

Incidencia inter-regional respecto a la renta media nacional OCDE, 2000 y 2004, ajustada movilidad, ramas y sexo

\begin{tabular}{|c|c|c|}
\hline & PHOGUE (2000) & ECV (2004) \\
\hline Andalucía & $2,38 \%$ & $1,73 \%$ \\
\hline Aragón & $3,02 \%$ & $2,95 \%$ \\
\hline Asturias & $2,45 \%$ & $2,65 \%$ \\
\hline Baleares & $1,88 \%$ & $1,88 \%$ \\
\hline Castilla La Mancha & $1,96 \%$ & $1,95 \%$ \\
\hline Castilla León & $3,19 \%$ & $2,67 \%$ \\
\hline Comunidad Valenciana & $2,89 \%$ & $3,26 \%$ \\
\hline Canarias & $2,33 \%$ & $2,23 \%$ \\
\hline Cantabria & $2,52 \%$ & $1,30 \%$ \\
\hline Cataluña & $3,19 \%$ & $2,53 \%$ \\
\hline Extremadura & $2,24 \%$ & $1,88 \%$ \\
\hline Galicia & $2,73 \%$ & $2,10 \%$ \\
\hline La Rioja & $3,24 \%$ & $2,74 \%$ \\
\hline Madrid & $4,25 \%$ & $2,02 \%$ \\
\hline Murcia & $3,05 \%$ & $2,61 \%$ \\
\hline Navarra & $3,06 \%$ & $4,40 \%$ \\
\hline País Vasco & $3,31 \%$ & $2,36 \%$ \\
\hline Media & $\mathbf{2 , 9 1 \%}$ & $\mathbf{2 , 3 4 \%}$ \\
\hline
\end{tabular}

Fuente: Elaboración propia a partir de PHOGUE, 2000 y ECV, 2004

\subsection{Incidencia intra-regional}

Los análisis de incidencia intra-regional se plantean desde una perspectiva personal, analizando la incidencia normativa del gasto público en educación universitaria dentro de cada una de nuestras regiones, considerada de forma aislada $^{16}$. En este sentido, el análisis se presenta desde una doble perspectiva, al igual que se ofrecía en el análisis realizado para el conjunto de la nación: por un lado, se ofrece un estudio de incidencia tradicional a través del cálculo de los pesos relativos del gasto público sobre la renta; por otro lado, se analiza el nivel de progresividad y redistribución del gasto en las diferentes regiones.

\footnotetext{
${ }^{16}$ Un ejemplo de este tipo de análisis es el estudio de Albaladejo Pina, I. P. Iglesias Vázquez, E.M (2001), para la región de Murcia.
} 
En la Tabla 6 se presenta un resumen de la incidencia calculada como el porcentaje que representa la importancia relativa del gasto medio en universidades por región, con respecto a la renta media de cada región. Los datos se presentan para las decilas más representativas (primera, quinta y última). Para el año 2000 (PHOGUE) algunas de las regiones muestran porcentajes de incidencia cercanos o superiores al 3\% en la primera decila (Asturias, Comunidad Valenciana, Extremadura, Galicia, Madrid, La Rioja Navarra y el País Vasco), las rentas medias, presentan una incidencia en torno al $2,6 \%$, mientras que la última decila es la más beneficiada, con una incidencia media superior al $4 \%$. Regiones que no siguen estos parámetros de incidencia son, por ejemplo, Asturias y La Rioja, con una incidencia más favorable a las rentas bajas, mientras que Madrid destaca por su elevada incidencia en las rentas altas.

En el caso de la ECV, los porcentajes de incidencia, tomados en promedio para decilas altas, bajas y medias, son bastante similares a los obtenidos con el PHOGUE. En concreto, para la decila más baja se obtiene un 2,76\%, para la quinta un $2,36 \%$, y para la última un $4,24 \%$. En este caso, las regiones que se salen de los valores promedios anteriores son Cantabria, Comunidad Valenciana y Navarra. Todas ellas presentan un impacto del gasto más elevado en la primera decila. Por el lado contrario, Aragón, Murcia, La Rioja, Extremadura, Asturias y Castilla León muestran índices de incidencia muy elevados en la última decila. En consecuencia, se podría decir que algunas regiones que presentan resultados favorables de incidencia con el PHOGUE, muestran datos de incidencia más negativos con la ECV.

Tabla 6.-

Resumen de resultados de incidencia intra-regional: incidencia respecto a la renta media total, por decilas de renta disponible OCDE, por CCAA, 2000 y 2004

\begin{tabular}{|c|c|c|c|c|c|c|c|c|c|c|}
\hline & & Andalucía & Aragón & Asturias & Baleares & C.LMancha & C.León & C.Valenciana & Canarias & Cantabria \\
\hline \multirow{4}{*}{ PHOGUE } & 1 & $2,12 \%$ & $2,12 \%$ & $3,05 \%$ & $1,88 \%$ & $2,09 \%$ & $2,68 \%$ & $4,83 \%$ & $1,39 \%$ & $2,54 \%$ \\
\hline & 5 & $2,52 \%$ & $2,52 \%$ & $2,02 \%$ & $2,65 \%$ & $2,05 \%$ & $2,47 \%$ & $3,89 \%$ & $2,47 \%$ & $2,81 \%$ \\
\hline & 10 & $2,28 \%$ & $2,28 \%$ & $1,63 \%$ & $2,46 \%$ & $3,39 \%$ & $3,52 \%$ & $4,93 \%$ & $4,36 \%$ & $3,62 \%$ \\
\hline & Media & $3,14 \%$ & $3,14 \%$ & $2,61 \%$ & $1,72 \%$ & $2,25 \%$ & $3,42 \%$ & $3,34 \%$ & $2,93 \%$ & $3,21 \%$ \\
\hline \multirow{4}{*}{ ECV } & 1 & $2,34 \%$ & $0,26 \%$ & $1,00 \%$ & $1,88 \%$ & $0,54 \%$ & $2,61 \%$ & $5,48 \%$ & $2,16 \%$ & $9,27 \%$ \\
\hline & 5 & $2,39 \%$ & $2,07 \%$ & $3,37 \%$ & $2,65 \%$ & $2,10 \%$ & $3,41 \%$ & $2,82 \%$ & $1,60 \%$ & $1,85 \%$ \\
\hline & 10 & $3,71 \%$ & $5,27 \%$ & $5,46 \%$ & $2,46 \%$ & $1,88 \%$ & $5,74 \%$ & $4,30 \%$ & $3,17 \%$ & $1,70 \%$ \\
\hline & Media & $2,21 \%$ & $2,85 \%$ & $2,49 \%$ & $1,72 \%$ & $2,38 \%$ & $3,01 \%$ & $3,56 \%$ & $2,66 \%$ & $1,38 \%$ \\
\hline
\end{tabular}




\begin{tabular}{|c|c|c|c|c|c|c|c|c|c|}
\hline & & Cataluña & Extremadura & Galicia & LaRioja & Madrid & Murcia & Navarra & P.Vasco \\
\hline \multirow{4}{*}{ PHOGUE } & 1 & $2,55 \%$ & $3,86 \%$ & $3,85 \%$ & $4,33 \%$ & $2,95 \%$ & $2,44 \%$ & $2,93 \%$ & $3,80 \%$ \\
\hline & 5 & $2,09 \%$ & $3,10 \%$ & $1,46 \%$ & $3,40 \%$ & $1,85 \%$ & $3,27 \%$ & $1,72 \%$ & $3,98 \%$ \\
\hline & 10 & $2,70 \%$ & $3,65 \%$ & $6,84 \%$ & $3,59 \%$ & $9,30 \%$ & $6,98 \%$ & $4,78 \%$ & $3,39 \%$ \\
\hline & Media & $2,89 \%$ & $3,40 \%$ & $3,22 \%$ & $3,24 \%$ & $3,87 \%$ & $3,64 \%$ & $3,22 \%$ & $2,95 \%$ \\
\hline \multirow{4}{*}{ ECV } & 1 & $1,48 \%$ & $0,86 \%$ & $2,97 \%$ & $2,71 \%$ & $2,28 \%$ & $1,05 \%$ & $8,30 \%$ & $1,79 \%$ \\
\hline & 5 & $1,78 \%$ & $2,19 \%$ & $1,55 \%$ & $2,10 \%$ & $1,72 \%$ & $2,31 \%$ & $5,15 \%$ & $1,05 \%$ \\
\hline & 10 & $3,79 \%$ & $7,41 \%$ & $4,20 \%$ & $5,91 \%$ & $3,74 \%$ & $6,68 \%$ & $4,46 \%$ & $2,13 \%$ \\
\hline & Media & $2,43 \%$ & $2,34 \%$ & $2,38 \%$ & $2,74 \%$ & $1,96 \%$ & $3,05 \%$ & $4,69 \%$ & $2,09 \%$ \\
\hline
\end{tabular}

Fuente: Elaboración propia a partir de PHOGUE, 2000 y ECV, 2004

En la Tabla 7 se presenta una clasificación de las CCAA según cuál sea su nivel de progresividad del gasto público en educación universitaria, y el impacto redistributivo que éste permite alcanzar. Los resultados demuestran que los logros distributivos en las regiones españolas son muy distintos, aunque todos progresivos y ligeramente redistributivos. Además, se observa que algunas regiones obtienen buenos resultados de incidencia con algunos indicadores y peores con otros. Los resultados varían de forma considerable según cual sea la base de datos tomada. Únicamente parece generalizable el caso de Navarra y País Vasco, que obtienen casi sistemáticamente los mejores resultados en todos los indicadores, mientras que Madrid destaca por lo contrario, sobre todo en el año 2000 .

Tabla 7.

Resumen de resultados de incidencia intra-regional: índices de progresividad (Kakwani), y redistribución (Reynolds-Smolensky), por CCAA, 2000 y 2004

\begin{tabular}{|c|c|c|}
\hline \multirow{5}{*}{ Progresividad K>0,24 } & $\begin{array}{c}\text { PHOGUE } \\
(\mathbf{2 0 0 0 )}\end{array}$ & ECV (2004) \\
\hline \multirow{5}{*}{} & Baleares & Andalucía \\
\cline { 2 - 3 } & C. León & C. León \\
\cline { 2 - 3 } & C. Valenciana & C. Valenciana \\
\cline { 2 - 3 } & & Cantabria \\
\cline { 2 - 3 } & Extremanana & \\
\cline { 2 - 3 } & Extremara & \\
\cline { 2 - 3 } & & Galicia \\
\cline { 2 - 3 } & La Rioja & \\
\cline { 2 - 3 } & Navarra & Navarra \\
\cline { 2 - 3 } & País Vasco & País Vasco \\
\hline
\end{tabular}




\begin{tabular}{|c|c|c|}
\hline & $\begin{array}{l}\text { PHOGUE } \\
(2000)\end{array}$ & ECV (2004) \\
\hline $\mathrm{K}$ (nacional) & 0,1816 & 0,1988 \\
\hline \multirow{3}{*}{ Progresividad $\mathrm{K}<0,07$} & & Aragón \\
\hline & Madrid & \\
\hline & Murcia & Murcia \\
\hline \multirow{2}{*}{ Redistribución > 0,01 } & Navarra & Navarra \\
\hline & País Vasco & \\
\hline RS (nacional) & 0,00571 & 0,00489 \\
\hline Redistribución < 0 & Madrid & \\
\hline
\end{tabular}

Fuente: Elaboración propia a partir de PHOGUE, 2000 y ECV, 2004

\section{CONCLUSIONES}

El trabajo que se presenta retoma los estudios tradicionales de incidencia normativa del gasto público, aplicados al caso concreto de la educación universitaria. La revisión de algunas de las aportaciones recientes más relevantes de la literatura pone de manifiesto una notable homogeneidad metodológica en las aplicaciones empíricas, lo cual tiene implicaciones importantes en los resultados desde el punto de vista del impacto distributivo del gasto público. En concreto, para España, la mayor parte de los trabajos realizados en los años noventa, pero sobre todo en la década de los ochenta, apuntan hacia un impacto del gasto más favorable hacia las rentas altas. Este efecto regresivo parece corregirse con el trascurso de los años y los análisis más recientes presentan impactos neutrales incluso progresivos. Fuera de España, sin embargo, los trabajos realizados presentan resultados más pesimistas. Metodológicamente, estos trabajos son similares a los realizados en España y aportan como conclusión, en general, que la incidencia de este gasto suele favorecer a rentas altas.

El estudio empírico de incidencia normativa realizado en el presente trabajo presenta novedades y aportaciones de singular importancia, siendo su principal finalidad contrastar cuál es la incidencia del gasto público universitario a partir del año 2000. Para ello, se realiza un estudio de incidencia normativa de este gasto para los años 2000 y 2004, incorporando una serie de decisiones metodológicas diferentes a las adoptadas en estudios anteriores. Entre éstas, cabe destacar lo novedoso de las bases de datos utilizadas (PHOGUE 2000 y ECV 2004), la unidad de análisis escogida y derivado de ello, las escalas de equivalencia que se aplican y los criterios de imputación del gasto que incorporan cuestiones de género, de especialidad de estudios y de movilidad universitaria. Además, los resultados se presentan a nivel nacional y regional, aspecto éste de gran importancia desde que en 1996 se produjera la descentralización de este gasto hacia las regiones españolas. 
Los principales resultados alcanzados a nivel nacional indican que la incidencia en España del gasto público en educación universitaria en 2000 y 2004, alcanza unos valores medios que se sitúan en torno al 3\%, si se mide la incidencia como la importancia que supone dicho gasto sobre la renta media disponible nacional total. Por grupos de renta, si tomamos como referente la renta media de cada decila, las primeras decilas son las que más se benefician de este gasto, cualquiera que sea la escala de equivalencia escogida. Cuando este indicador de incidencia se calcula respecto de la renta media del total de la población, la proporción entre subvención y renta se invierte, siendo las decilas más altas las más beneficiadas. En cualquier caso, la incidencia media del gasto público en educación universitaria es bastante más elevada que la resultante en estudios anteriores.

El grado de progresividad que presentan las subvenciones a la educación universitaria es notable, tanto con los datos de 2000 (PHOGUE), como de 2004 $(\mathrm{ECV})$, cualesquiera que sea la escala de equivalencia aplicada. En concreto, con la escala general de la OCDE, el índice de progresividad de Kakwani es positivo y presenta un valor que está alrededor del 0,2. También en este caso los valores alcanzados son superiores a los resultantes en estudios anteriores. Por lo que se refiere a las becas, y en este caso con datos de la ECV (2004) dado que es la única que contiene la información necesaria, el índice de progresividad $\left(\mathrm{K}_{\mathrm{b}}\right)$ es realmente elevado. $\mathrm{Y}$ esto es así sea cual sea la escala de equivalencia seleccionada: $0,65293_{\text {OCDE }} ; 0,65353_{\text {OCDESP }} ; 0,63308_{\text {OCDEMOD }} ; 0,53928_{\text {BUHMANN. }}$.

En cuanto al impacto distributivo originado por las subvenciones a la educación universitaria, todos los valores de los índices de Reynolds-Smolesky son positivos, lo que indica que se trata de un gasto redistributivo además de progresivo. Sin embargo, los valores son realmente pequeños lo que muestra impactos redistributivos bajos, lo cual es esperable, dada la baja cuantía de este tipo de gasto. Por otra parte, los valores del $\mathrm{RS}_{\mathrm{s}}$ ( $\sin$ reordenación) son superiores que los del $\mathrm{RS}_{\mathrm{s}}{ }^{*}$ (con reordenación), puesto que $\mathrm{RS}_{\mathrm{s}}$ incorpora el efecto provocado por la reordenación.

Centrándonos en la incidencia inter-regional, la importancia relativa del gasto en educación universitaria en cada región con respecto a la renta media nacional, parece ser muy dispar. Además, los resultados varían considerablemente según cuál sea la base de datos. Con el PHOGUE (2000) las comunidades que presentan mayores porcentajes de incidencia son: Madrid, Castilla-León o el País Vasco, con valores por encima del 3\%. Por el contrario, Baleares no alcanza el 2\%. Con la ECV (2004) es Navarra la que presenta los valores más elevados y Baleares sigue siendo de las que registran menores porcentajes, junto con Extremadura y Andalucía.

También son muy dispares los resultados alcanzados en el análisis de la incidencia intra-regional, esto es, cuando se analiza el impacto distributivo 
alcanzado por este gasto en cada región considerada de forma aislada. En este caso, hay regiones que presentan índices de incidencia elevados en la primera decila y regiones que presentan el resultado contrario. Además, los resultados obtenidos varían considerablemente según la fuente de datos tomada. Tan solo Navarra, Extremadura y La Rioja, muestran con ambas fuentes de datos, el mismo impacto. Navarra siempre presenta una incidencia favorable a rentas bajas y Extremadura y la Rioja, justamente lo contrario.

En términos de evolución de la incidencia entre 2000 y 2004, se puede decir que parece existir una menor incidencia cuando ésta se calcula como porcentaje de la renta, existiendo diferencias entre ambos años en cuanto a los resultados presentados para cada región por los indicadores de desigualdad, progresividad y redistribución, en el sentido de que algunas regiones presentan incrementos en el valor de los índices en este periodo, mientras que otras disminuyen. En términos generales, la evaluación de la incidencia del gasto público en educación universitaria muestra importantes diferencias en cuanto a su impacto por regiones y parece no existir una pauta clara en la evolución de dicha incidencia, aunque se recuerda la diferente procedencia de las bases de datos empleadas. Por ello, es importante señalar la importancia del análisis a nivel regional, puesto que se evidencian las disparidades entre comunidades, las cuales no se muestran en un estudio a nivel nacional.

En definitiva, se puede afirmar que el impacto distributivo del gasto publico en educación universitaria es más elevado en el nuevo milenio que en décadas anteriores, este impacto además, es levemente progresivo y redistributivo y se distribuye de forma bastante dispar entre las diferentes Comunidades Autónomas. En cualquier caso, estos resultados indican que existe una tendencia al mayor aprovechamiento de este gasto por todos los grupos de renta, aunque con bastante disparidad entre regiones (aunque casi todas con resultados positivos en términos distributivos). No se aprecia tampoco una clara relación positiva entre las regiones con mayores aumentos del gasto público (totales o per capita) y mejoras en los resultados de incidencia del gasto.

En términos de política económica, esto parece implicar que, aunque los resultados distributivos parecen positivos para casi todas las regiones, el sistema de financiación de este nivel educativo, altamente descentralizado, no está suponiendo una reducción en las desigualdades territoriales.

\section{REFERENCIAS BIBLOGRÁFICAS}

ALBALADEJO PINA, I. P. IGLESIAS VÁZQUEZ, E.M (2001) “ Características familiares de los jóvenes que cursan estudios postobligatorios en la región de Murcia". Estudios de Economía Aplicada 17, pp. 69-83. 
AL-SAMARRAI, S., ZAMAN, H. (2002): "The Changing Distribution of Public Education Expenditure in Malawi". Africa Region Working Papers Series, $\mathrm{n}^{\circ}$ 29, marzo 2002.

ANTONINIS, M. TSAKLOGLOU, P. (2001) "Who benefits from public education in Greece? Evidence and policy implications". Education Economics, vol. 9, $n^{\circ}$ 3, agosto 2001, pp. 197-222.

BORRAZ, S. CID, A.I., CORCHUELO, B. Y MONEO, C. (1996) "Efectos redistributivos de las becas universitarias por Comunidades Autónomas". III Encuentro de Economía Pública, Sevilla, 1996.

BAREA, J. ET AL. (1990) "Incidencia del gasto público en España. Análisis del colectivo de beneficiarios". Monografía no 91 . Instituto de Estudios Fiscales.

BUHMANN, B. et al. (1988) "Equivalence scales, well-being, inequality and poverty: sensitivity estimates across ten countries using the Luxembourg Income Study (LIS) data." Review of Income and Wealth, vol. 34, pp.115142.

CALERO, J. (1996) "Financiación de la educación universitaria en España: sus implicaciones en el terreno de la equidad". Fundación BBV.

CALERO, J. (1998) "El gasto en educación universitaria y la equidad: Educación y empleo". Hacienda Pública Española, Monografías, 1998, pp.89-100.

CALERO, J. (2001) "La incidencia distributiva del gasto público social. Análisis general y tratamiento específico de la incidencia distributiva entre grupos sociales y entre grupos de edad". Trabajo de investigación presentado al concurso para la provisión de una plaza de Catedrático de Universidad en el Área de conocimiento "Economía Aplicada". Barcelona, mayo de 2001.

CALERO, J. (2002) "The Distribution of Public Social Expenditure in Spain: General Analysis with Special Reference to age and social class". Social Policy \& Administration, vol. 36, no. 5, pp. 443-464.

CONSEJO DE UNIVERSIDADES (1995) "Informe sobre la financiación de las universidades", Madrid.

DE PABLOS, L., VALIÑO, A. (2000) "Economía del gasto público: control y evaluación". Ed. Civitas, pp.271-313.

DE WULF, L. (1981): "Incidence of Budgetary Outlays: Where do we go from here". Public Finance, vol. 36, n 1 . Versión en español (1987) "Incidencia del gasto: ¿Hacia donde vamos ahora?". Hacienda Pública Española, 107, pp. 107-120.

DEMERY, LIONEL (2000) "Benefit Incidence: A practitioner's guide". World Bank. Poverty and Social Development Group. Africa Region.

ENCUESTA DE CONDICIONES DE VIDA (varios años). Instituto de Estudios Fiscales.

GIL, M. (2005) "Análisis de incidencia del gasto público en Educación Superior: nuevas aproximaciones". Papeles de Trabajo, $\mathrm{n}^{\circ}$ 10/2005. Instituto de Estudios Fiscales. 
GIMENO, J. A. (2000) "La incidencia redistributiva del gasto público en España". En Rafael Muñoz de Bustillo (ed.), El Estado de Bienestar en el cambio de siglo. Capítulo 8.Alianza Editorial.

HARBERGER, A. C. (2004) "Taxation and income distribution: myth and realities". Mimeo. August.

KAKWANI, N. C. (1977) "Measurement of Tax Progressivity: An international Comparison", Economic Journal, vol. 87 (345), pp. 71-80.

LÓPEZ-ACEVEDO Y SALINAS, A. (2000) "Marginal Willingness to Pay for Education and the Determinants of Enrollment in Mexico" Policy Research Working Paper 2405. The World Bank Latin America and the Caribbean Region Economic Policy Sector Unit and Mexico Country Office.

LÓPEZ AFONSO CASADO, J.M. M. HERNÁNDEZ LÓPEZ (1998) "Una panorámica regional de la educación superior en España". Estudios de Economía Aplicada 10, pp 5-18.

MARCENARO GUTIÉRREZ, O. D. Y NAVARRO GOMEZ, M. L (2001) "Un análisis microeconómico de la demanda de educación superior en España". Estudios de Economía Aplicada. 19 pp 69-86.

MINISTERIO DE EDUCACIÓN Y CULTURA (1995 a 2008) "Las cifras de la Educación en España. Estadísticas e Indicadores." Disponible en http://www.educacion.es/mecd/jsp/plantilla.jsp?id=3131\&area=estadisticas\& contenido=/estadisticas/educativas/cee/2007A/cee-2007A.html (Fecha de la última consulta: 20 de septiembre de 2010).

MINISTERIO DE EDUCACIÓN Y CULTURA Y DEPORTE (2000 a 2007) "Sistema Estatal de Indicadores de la Educación." Disponible en http://www.educacion.es/mecd/jsp/plantilla.jsp?id=3132\&area=estadisticas (Fecha de la última consulta: 20 de septiembre de 2010).

MINISTERIO DE EDUCACIÓN Y CULTURA Y DEPORTE (2006) "Estadística del gasto público en Educación. Presupuesto Liquidado. Años 1997 a 2004." Disponible en www.mecd.es

MINISTERIO DE EDUCACIÓN, CULTURA Y DEPORTE (1999) "Estadística del gasto público en Educación. Presupuesto Liquidado. Años 1992 a 1997." Disponible en www.mecd.es

MORA RUIZ, J. (1996) "Equidad en el acceso a la educación superior: ¿Para quiénes son las becas?" Revista de Educación, nº 309, pp. 239-259.

PANEL DE HOGARES DE LA UNIÓN EUROPEA (varios años). Instituto Nacional de Estadística.

PÉREZ ESPARRELLS, M.C. (1996a) "Aspectos económicos de la intervención pública en la financiación de la educación superior: un análisis de los efectos distributivos del gasto público en enseñanza universitaria en España (1981 y 1991)". Tesis Doctoral, Universidad Complutense de Madrid.

PÉREZ ESPARRELLS, M.C. (1996b) "Un análisis de los efectos redistributivos del gasto público en enseñanza universitaria en España (1981 y 1991). Una 
aproximación a la incidencia espacial". III Encuentro de Economía Pública, Sevilla, 1996.

PÉREZ ESPARRELLS, M.C., UTRILLA DE LA HOZ, A. (1996) "La incidencia redistributiva del gasto público en educación: una aproximación empírica al caso español". Documento de Trabajo № 9609. Universidad Complutense de Madrid. Disponible en http://www.ucm.es/BUCM/cee/doc/0028/03010028.htm (Fecha de la última consulta: 20 de septiembre de 2010).

REYNOLDS, M., Y SMOLENSKY, E. (1977) "Public Expenditure, Taxes and the Distribution of Income: The United States, 1950, 1961, 1970. Academic Press, Nueva York.

RICHARDSON, S. (1985): "Who benefits from higher education?" Flinders University of South Australia. National Institute of Labour Studies Incorporated. Working Paper $\mathrm{n}^{\circ} 75$.

SÁNCHEZ CAMPILLO, J. (1996) "Los efectos distributivos del gasto público destinado a enseñanza superior en la universidad de Granada y en España". Granada, Universidad de Granada.

SELOWSKY, M. (1979): "Who benefits from goverment expenditure?: A case of study of Colombia." Oxford University Press, pp. 50-70.

URSICINO CARRASCAL A. (1996) "Estimación de escalas de equivalencia de consumo mediante un modelo de demanda casi ideal (AIDS) ampliado". Estudios de Economía Aplicada .6, pp25-38

VAN DE WALLE, D. (1998) "Assessing the Welfare Impacts of Public Spending". World Developement 26, 3. Pp. 365-379. 


\section{ANEXO}

Tabla 1.

Características, ventajas y limitaciones del PHOGUE y la ECV

\begin{tabular}{|c|c|c|}
\hline \multicolumn{3}{|c|}{ Características generales } \\
\hline & PHOGUE & ECV \\
\hline $\begin{array}{l}\text { Tipo de } \\
\text { encuesta }\end{array}$ & $\begin{array}{l}\text { Diseño de panel fijo puro, } \\
\text { manteniendo a los hogares } \\
\text { elegidos en el primer periodo, } \\
\text { siguiendo a sus miembros y } \\
\text { permitiendo nuevas entradas. }\end{array}$ & $\begin{array}{l}\text { Diseño de panel rotatorio anual, con } \\
\text { turno de rotación* de } 1 / 4 \text { cada año. }\end{array}$ \\
\hline Objetivos & $\begin{array}{l}\text { Instrumento de observación } \\
\text { estadística para el estudio y } \\
\text { seguimiento del nivel de vida, } \\
\text { las condiciones del mercado de } \\
\text { trabajo y la cohesión social, a } \\
\text { nivel de la UE. }\end{array}$ & $\begin{array}{l}\text { Estimaciones a nivel europeo sobre } \\
\text { la renta y las condiciones de vida, } \\
\text { con datos transversales y } \\
\text { longitudinales comparables y } \\
\text { actualizados sobre la renta, el nivel y } \\
\text { composición de la pobreza y la } \\
\text { exclusión social, a escala nacional y } \\
\text { europea. }\end{array}$ \\
\hline $\begin{array}{l}\text { Periodos } \\
\text { disponibles }\end{array}$ & $\begin{array}{l}\text { Años } 1994 \text { a 2001. Para el año } \\
2000 \text { se dispone de una muestra } \\
\text { ampliada. }\end{array}$ & Años 2004 y 2005. \\
\hline $\begin{array}{l}\text { Tamaño de la } \\
\text { muestra } \\
\text { (referido al } \\
\text { hogar) }\end{array}$ & $\begin{array}{l}\text { - Número de hogares totales } \\
\text { originales, por año, } \\
\text { respectivamente: } 7.206,6.522 \text {, } \\
6.267,5.794,5.485,5.418, \\
5.132,4.966 . \\
\text { - Número de hogares totales } \\
\text { para la muestra ampliada de } \\
\text { 2000: } 15.614 .\end{array}$ & $\begin{array}{l}15.355 \text { hogares en el año } 2004 \text { y } \\
12.996 \text { en el año } 2005 .\end{array}$ \\
\hline $\begin{array}{l}\text { Unidad } \\
\text { muestral }\end{array}$ & $\begin{array}{l}\text { Hogares privados y sus } \\
\text { miembros, y a partir de la } \\
\text { segunda ola, se añaden los } \\
\text { hogares privados o colectivos } \\
\text { que se hayan formado. }\end{array}$ & $\begin{array}{l}\text { Hogares observados en viviendas } \\
\text { familiares y sus miembros. }\end{array}$ \\
\hline $\begin{array}{l}\text { Variables } \\
\text { referidas }\end{array}$ & $\begin{array}{l}\text { Al hogar y a los miembros de } \\
\text { cada hogar. }\end{array}$ & $\begin{array}{l}\text { Al hogar y a los miembros de cada } \\
\text { hogar. }\end{array}$ \\
\hline $\begin{array}{l}\text { Variables de } \\
\text { poder } \\
\text { adquisitivo }\end{array}$ & $\begin{array}{l}\text { - Rentas del hogar y de cada } \\
\text { uno de sus miembros, } \\
\text { detalladas según la procedencia } \\
\text { de las rentas. } \\
\text { - Salarios detallados de cada } \\
\text { uno de sus miembros. }\end{array}$ & $\begin{array}{l}\text { - Rentas del hogar y de cada uno de } \\
\text { sus miembros, detalladas según } \\
\text { procedencia de dichas rentas. } \\
\text { - Salarios de cada uno de sus } \\
\text { miembros. }\end{array}$ \\
\hline
\end{tabular}




\begin{tabular}{|c|c|c|}
\hline \multicolumn{3}{|c|}{ Características para el análisis de incidencia normativa del gasto público } \\
\hline & PHOGUE & ECV \\
\hline $\begin{array}{l}\text { Periodo de } \\
\text { análisis } \\
\text { seleccionado }^{17 .}\end{array}$ & Año 2000 (muestra ampliada). & Año 2004. \\
\hline $\begin{array}{l}\text { Ventajas de la } \\
\text { encuesta }\end{array}$ & $\begin{array}{l}\text { - Elevado tamaño muestral. } \\
\text { - Información detallada por CCAA } \\
\text { para el año } 2000 . \\
\text { - Información muy detallada a } \\
\text { nivel de hogar e individuo. }\end{array}$ & $\begin{array}{l}\text { - Elevado tamaño muestral. } \\
\text { - Información detallada por CCAA. }\end{array}$ \\
\hline $\begin{array}{l}\text { Limitaciones } \\
\text { de la encuesta }\end{array}$ & $\begin{array}{l}\text { Fundamentalmente derivadas de } \\
\text { su estructura de panel, surgen en } \\
\text { la explotación longitudinal } \\
\text { (attrition, p.e.). }\end{array}$ & $\begin{array}{l}\text { Elevado porcentaje de falta de } \\
\text { respuesta en el cuestionario } \\
\text { individual para algunos hogares, no } \\
\text { aleatoriamente distribuido por } \\
\text { CCAA, edad, sexo, etc. en } 2004 \text {. }\end{array}$ \\
\hline $\begin{array}{l}\text { Ventajas para } \\
\text { el análisis de } \\
\text { incidencia del } \\
\text { gasto }\end{array}$ & $\begin{array}{l}\text { Dispone de información detallada } \\
\text { de cada uno de los miembros del } \\
\text { hogar, lo que permite conocer el } \\
\text { número de individuos en } \\
\text { educación universitaria. }\end{array}$ & $\begin{array}{l}\text { Dispone de información detallada } \\
\text { de cada uno de los miembros del } \\
\text { hogar, lo que permite conocer el } \\
\text { número de individuos en educación } \\
\text { universitaria. }\end{array}$ \\
\hline $\begin{array}{l}\text { Limitaciones } \\
\text { para el análisis } \\
\text { de incidencia } \\
\text { del gasto }\end{array}$ & $\begin{array}{l}\text { - No dispone de información } \\
\text { relativa al gasto privado realizado } \\
\text { por los hogares. } \\
\text { - No contiene información } \\
\text { detallada sobre el tipo de } \\
\text { estudios realizados por cada } \\
\text { individuo, ni sobre la localización } \\
\text { de la universidad de estudio. }\end{array}$ & $\begin{array}{l}\text { - No dispone de información } \\
\text { relativa al gasto privado realizado } \\
\text { por los hogares. } \\
\text { - No contiene información detallada } \\
\text { sobre el tipo de estudios realizados } \\
\text { por cada individuo, ni sobre la } \\
\text { localización de la universidad de } \\
\text { estudio. }\end{array}$ \\
\hline
\end{tabular}

En los paneles rotantes se entrevista a las mismas unidades muestrales durante una serie de periodos, renovándose cada periodo una parte de la muestra. Por ejemplo, en el caso de una rotación trimestral de 1/8, estaríamos diciendo que cada trimestre se renueva 1/8 de la muestra.

Fuente: Elaboración propia a partir de PHOGUE (1994-2001) y ECV (2004-2005).

${ }^{17}$ Hay que señalar que las variables de renta tanto en el PHOGUE como en la ECV, se refieren al periodo anterior, es decir, a 1999 y a 2003, respectivamente. Por ello, el dato del gasto público (Tabla 2) también se refiere al mismo periodo. 
Tabla 2.

Gasto público total en educación universitaria en España per capita y por CCAA, 1999 y 2003 (euros), ajustada movilidad, ramas y sexo

\begin{tabular}{ccccc}
\hline & \multicolumn{2}{c}{1999} & \multicolumn{2}{c}{2003} \\
& Hombre & Mujer & Hombre & Mujer \\
\hline Andalucía & 2.649 & 2.844 & 4.649 & 4.329 \\
Aragón & 2.942 & 3.175 & 5.049 & 4.666 \\
Asturias & 3.030 & 3.312 & 4.681 & 4.257 \\
Baleares & 3.040 & 3.208 & 4.803 & 4.507 \\
Canarias & 3.517 & 3.747 & 5.347 & 4.970 \\
Cantabria & 3.725 & 4.046 & 5.584 & 5.152 \\
C.León & 3.335 & 3.553 & 4.979 & 4.665 \\
C.LMancha & 2.571 & 2.733 & 5.362 & 5.021 \\
Cataluña & 3.722 & 3.984 & 5.308 & 4.938 \\
C.Valenciana & 3.766 & 4.039 & 6.541 & 6.084 \\
Extremadura & 3.103 & 3.333 & 4.132 & 3.880 \\
Galicia & 3.074 & 3.255 & 4.437 & 4.184 \\
Madrid & 3.390 & 3.579 & 5.329 & 5.022 \\
Murcia & 3.688 & 3.911 & 5.243 & 4.914 \\
Navarra & 4.196 & 4.378 & 7.048 & 6.756 \\
P.Vasco & 3.645 & 3.976 & 5.370 & 4.919 \\
La Rioja & 3.595 & 3.857 & 4.930 & 4.612 \\
\hline
\end{tabular}

Fuente: Elaboración propia a partir de Ministerio de Educación, Cultura y Deporte y Consejo de Universidades (varios años). 
